\title{
OUTCOMES IN AN ELDERLY SEPTIC SURGICAL PATIENTS COHORT
}

\author{
Pérez González, A*.; Martín Alfonso, S.*; López del Moral López, 0*., Almudí Ceinos, D*.; Rico Feijoo, J*; Aldecoa-Álvarez - \\ Santullano. C* \\ *Hospital Universitario Río Hortega. Valladolid. Spain.
}

OBJETIVES
To determine differences in mortality of postsurgical septic
patients according to age groups, as well as their association with
different factors such as renal failure, renal replacement therapy
and / or mechanical ventilation. We also want to know the
severity of illness measured by SOFA score and its impact
in elderly mortality

\section{MATERIAL AND METHODS}

\section{Observational, retrospective study}

- Patients admitted to the ICU of the University Hospital of Río Hortega de Valladolid.

- More than 48 hours.

- Criteria of sepsis, severe sepsis or septic shock.

- From January 2011 to January 2016.

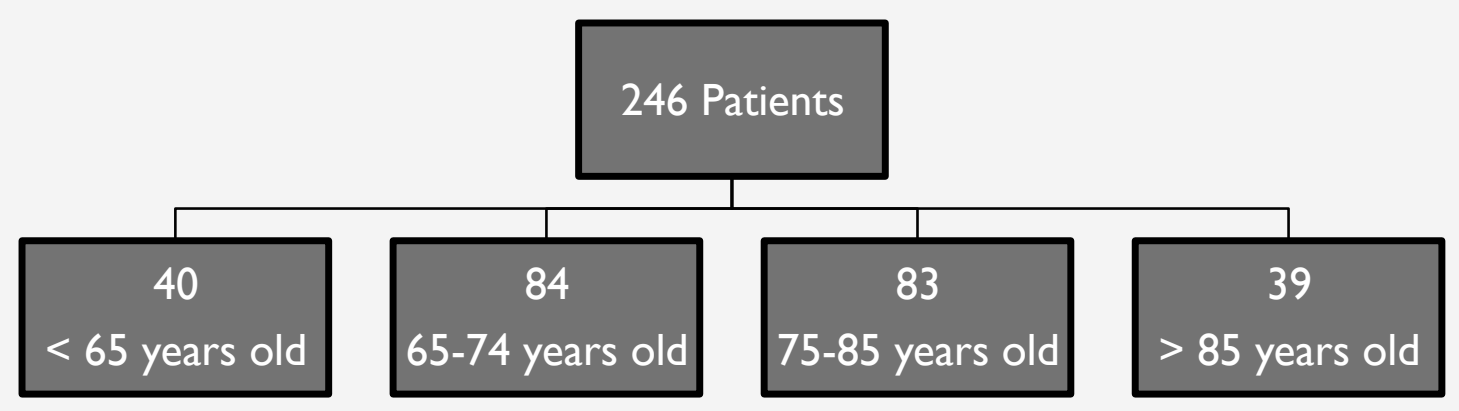

Statistical analysis Chi-Square test was used to study the relationship between the qualitative variables and the Student's T-test for the quantitative variables.

\section{Variables:}

1. Age, divided into groups.

2. Sex.

3. Diagnosis of sepsis, severe sepsis or septic shock.

4. SOFA scale at $24 \mathrm{~h}$ of admission and during the first 7 days of recovery. APACHE II scale at $24 \mathrm{~h}$ of admission.

5. Presence of comorbidities (two groups: $<2$ comorbidities and $>2$ ).

6. Acute renal failure, need for renal replacement therapy, need for mechanical ventilation

7. Stay in resuscitation unit,

8. Mortality in ICU unit, at 28 days, 6 months and 1 year before.

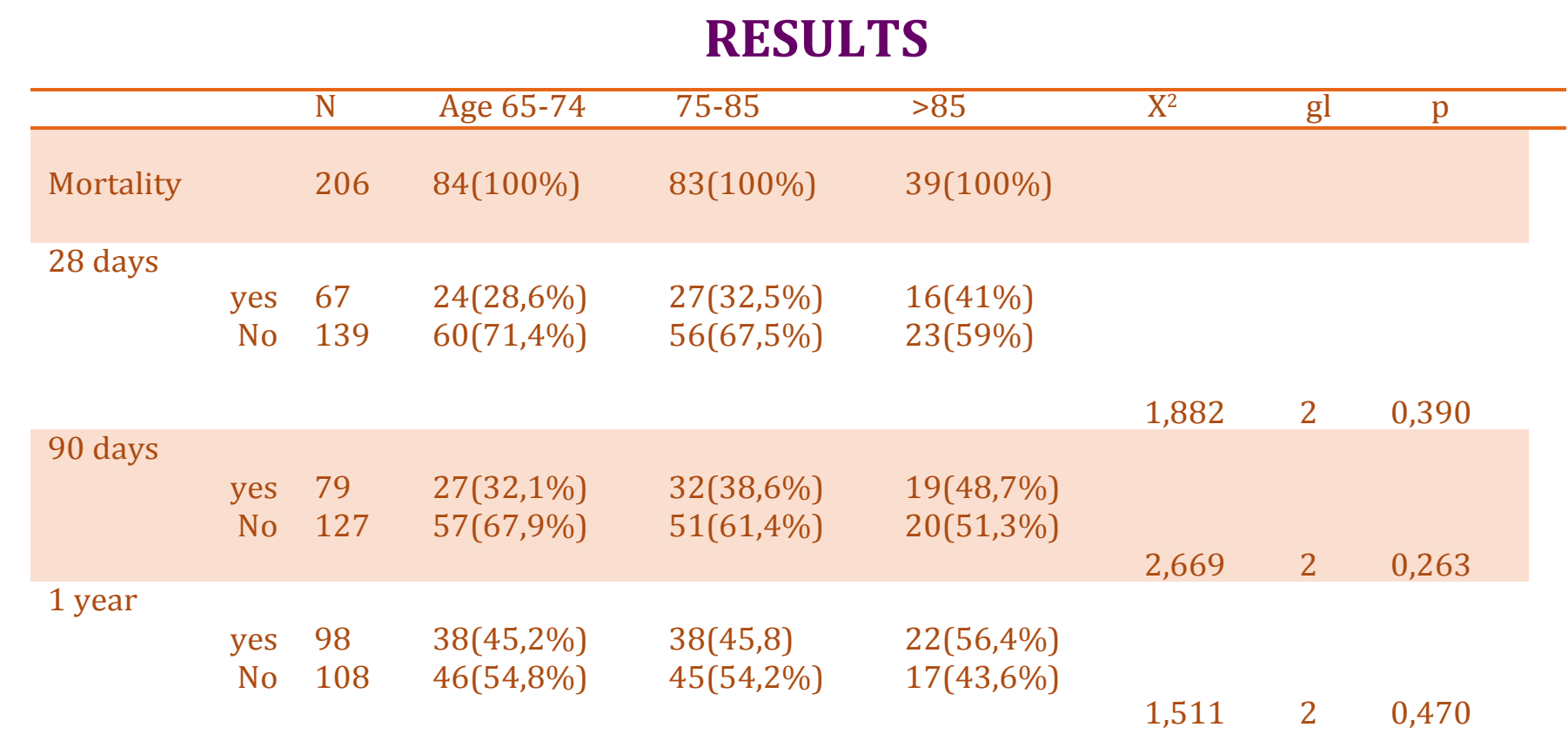

Table 1:Mortality by group of age and period of time.
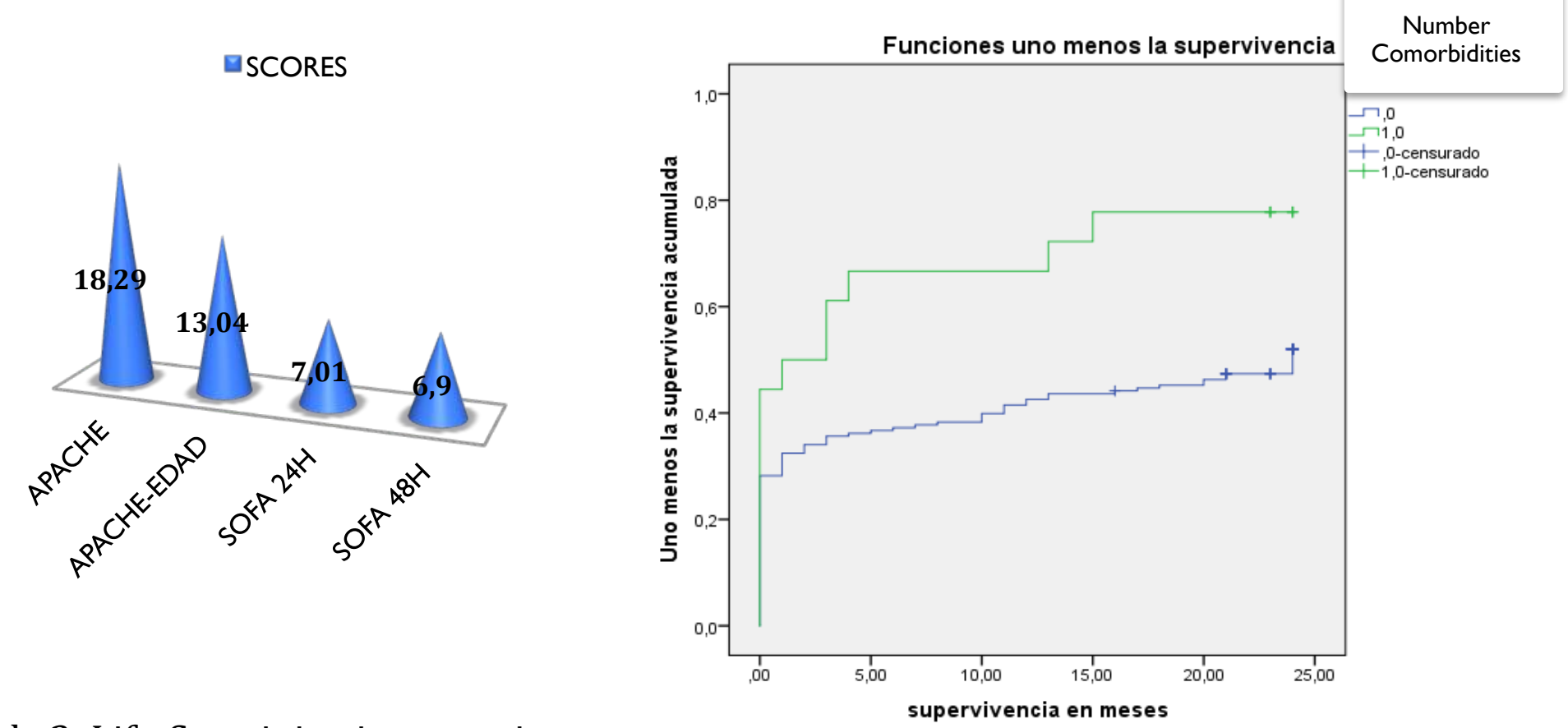

Table 3: Life-Sustaining interventions
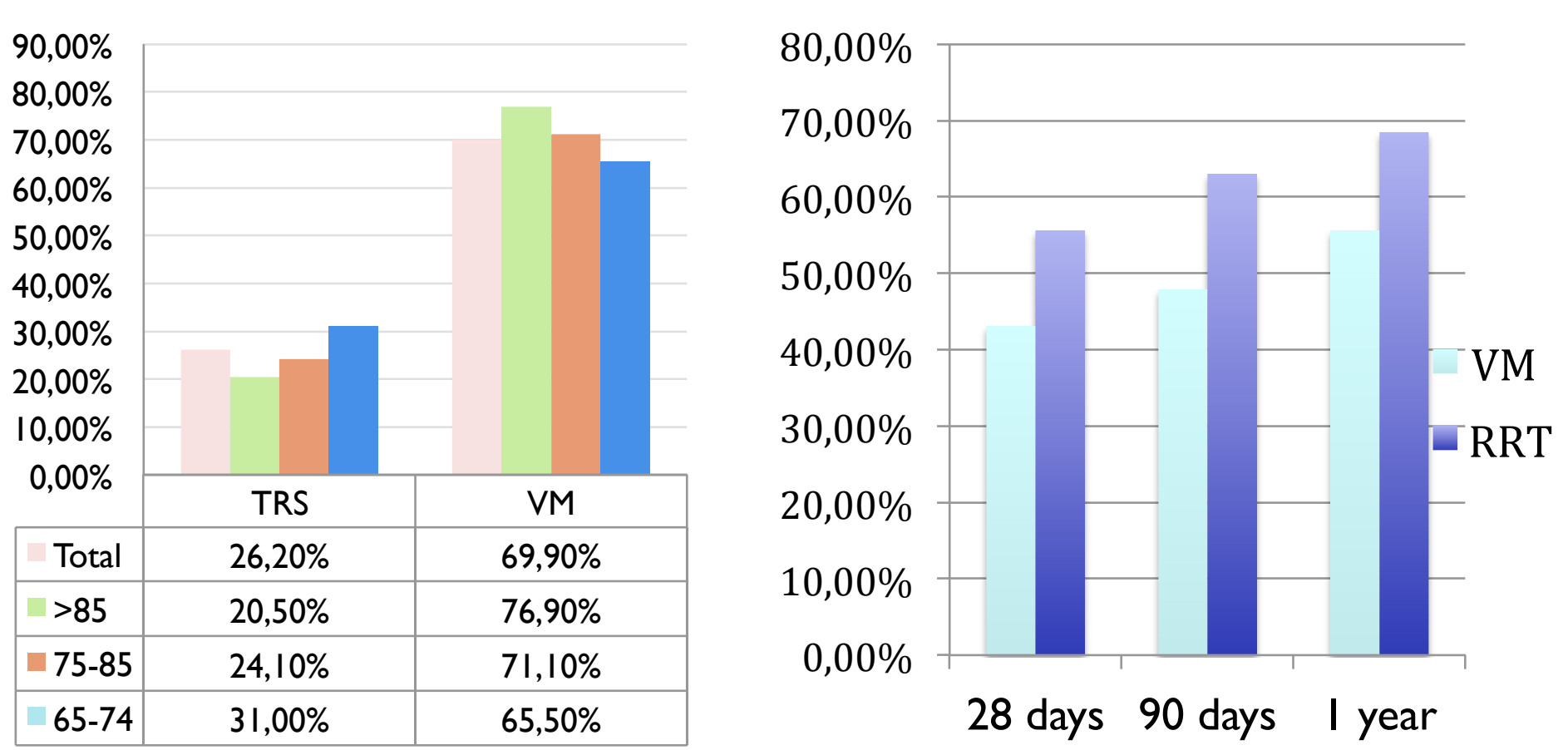

Table 4: mortality by RRT and VM

\section{CONCLUSION}

Recent studies show a mortality rate higher than $65 \%$. But until the date, no cohorts of surgical septic patients have been published. In our study, mortality was increased according to comorbidity ( $p$ 0.05), which may be an independent factor of mortality, and not only age, as reported in previous studies. We did not obtain as high values of mortality in elderly patients $>85$ years as those reported before. Therefore, we believe that new prospective studies with a larger sample size should be carried out to confirm these data 